\title{
Fluxos migratórios na globalização: imigração senegalesa no extremo sul do Brasil
}

\author{
Flujos migratorios en la globalización: inmigración senegalesa en el \\ extremo sur de Brasil \\ Migratory flows in globalization: Senegalese immigration in the south of \\ Brazil
}

\author{
Nilton Garcia Sainz ${ }^{1}$
}

\begin{abstract}
Resumo
Entre os anos de 2013 e 2014, ocorreu no Brasil uma onda imigratória contemporânea, dessa vez proveniente do Haiti e do continente Africano. Percentualmente, nas duas últimas décadas, a população do continente africano foi a que mais imigrou para o Brasil. Sob essa perspectiva, por meio deste estudo será abordado o fenômeno social das migrações, mais precisamente a problematizar a imigração senegalesa no município de Rio Grande, no Rio Grande do Sul (RS). Diante disso, a questão central a ser trabalhada nesse artigo é: Qual a influência dos fluxos migratórios, no caso da senegalesa, nas reconfigurações das dinâmicas sociais no município de Rio Grande? O objetivo geral é analisar a reconfiguração de dinâmicas sociais locais junto aos fluxos imigratórios na atualidade, em especial a partir do ano de 2010. A pesquisa é qualitativa, e é realizada através de pesquisa exploratória, observação direta, depoimentos de imigrantes e analise de conteúdo em reportagens jornalísticas. Desse modo, o estudo reflete também sobre o fluxo migratório e as inter-relações entre os senegaleses e a população riograndina no mercado de trabalho e na organização política.
\end{abstract}

Palavras-Chave: Imigrações; Globalização; Trabalho; Identidades; Rio Grande.

\section{Resumen}

Entre los años de 2013 y 2014, ocurrió en Brasil una ola inmigratoria contemporánea, esta vez proveniente de Haití y del continente africano. La población del continente africano fue la que más inmigró a Brasil en porcentaje, en las dos últimas décadas. En esta perspectiva, por este estudio se abordará el fenómeno social de las migraciones, más precisamente a problematizar la inmigración senegalesa en el municipio de Rio Grande, en Rio Grande do Sul (RS). En el caso de la senegalesa, en la reconfiguración de las dinámicas sociales en el municipio de Rio Grande, la cuestión central a ser trabajada en ese artículo es: ¿Cuál es la influencia de los flujos migratorios, en el caso de la senegalesa, en las reconfiguraciones de las dinámicas sociales en el municipio de Rio Grande? El objetivo general es analizar la reconfiguración de dinámicas sociales locales junto a los flujos inmigratorios en la actualidad, en especial a partir del año 2010. La investigación es cualitativa, y se realiza a través de investigación exploratoria, observación directa, testimonios de inmigrantes y análisis de contenido en reportajes periodísticos. De ese modo, el estudio refleja también sobre el flujo migratorio y las interrelaciones entre los senegaleses y la población riograndina en el mercado de trabajo y en la organización política.

Palabras claves: Inmigración; Globalización; Trabajo; Identidades; Rio Grande.

\footnotetext{
${ }^{1}$ Graduando em Ciências Sociais Bacharelado pela Universidade Federal de Pelotas, bolsista de iniciação cientifica do CNPQ e membro do grupo de pesquisa em Dinâmicas Políticas, Estado e Movimentos Sociais DIPEM, da Universidade Federal de Rio Grande. Um agradecimento especial ao Prof. Dr. Sérgio Botton Barcellos pela orientação desta pesquisa; Rio Grande, Rio Grande do Sul, Brasil; niltonsainz@ig.com.br.
} 


\begin{abstract}
Between the years of 2013 and 2014, a contemporary migratory wave occurred in Brazil, this time coming from Haiti and the African continent. The population of the African continent was the most immigrated to Brazil in percentage, in the last two decades. In this perspective, this study will address the social phenomenon of migration, more precisely to problematize Senegalese immigration in the municipality of Rio Grande, Rio Grande do Sul (RS). In the case of the Senegalese, in the reconfiguration of the social dynamics in the municipality of Rio Grande, the central question to be worked on that article is: what is the influence of migratory flows, in the case of Senegalese, in the reconfigurations of the Social Dynamics in the municipality of Rio Grande? The general objective is to analyze the reconfiguration of local social dynamics together with the migratory flows at the present time, especially from the year 2010. The research is qualitative, and is carried out through exploratory research, direct observation, immigrant testimonials and content analysis in journalistic reports. In this way, the study also reflects on the migratory flow and the interrelations between the Senegalese and the Riograndina population in the labour market and in the political organization.
\end{abstract}

Keywords: immigration; Globalization; Work; Identity; Rio Grande.

\title{
1. Introdução e problema de pesquisa
}

Este trabalho versa sobre um tema atual e de relevância para a sociologia contemporânea. Trata-se de um estudo sobre as imigrações. Mais especificamente o fluxo imigratório senegalês para o Brasil, nesse caso para o município de Rio Grande, no estado do Rio Grande do Sul (RS). Proporcionalmente, sabe-se que o continente africano é o maior emissor de imigrantes para o Brasil (UEBEL, 2015, p.92), grande parte desses imigrantes são homens, com formação superior, bilíngue, e que buscam uma mistura de opções de trabalho e garantias legais.

Entre os anos de 2013 e 2014, acontece no Brasil o chamado boom imigratório, que resultou na elevação do número de imigrantes no país. Assim, é possível observar nos municípios a presença de novos atores e grupos sociais. No estado do Rio Grande do Sul, entre os anos de 2013-2014, a imigração senegalesa passou a ocupar a $16^{\circ}$ posição no ranking de concentração de imigrantes presentes no estado, o que a coloca a frente dos números de outros países na qual já tiveram uma maior visibilidade, como o caso dos libaneses e paraguaios (UEBEL, 2015, p.173). No município de Rio Grande, estima-se que moram cerca de 200 imigrantes $^{2}$ senegaleses, em grande maioria homens. Algo que vem chamando a atenção da população, das instituições municipais e que também motivou a realização deste estudo.

Sob essa perspectiva, por meio deste estudo será problematizada a imigração senegalesa no município de Rio Grande, no Rio Grande do Sul (RS). Diante disso, a questão central a ser trabalhada é: Qual a influência dos fluxos migratórios, no caso da senegalesa, nas

\footnotetext{
${ }^{2}$ Vale ressaltar a dificuldade existente em obter números precisos acerca da atual fase das imigrações no país. A estimativa que se faz é com base em um levantamento de um periódico local (Jornal Agora) e com base nas entrevistas concedidas pelos membros da Associação Senegalesa de Rio Grande.
} 
reconfigurações das dinâmicas sociais no município de Rio Grande? O objetivo geral é analisar a reconfiguração de dinâmicas sociais locais junto aos fluxos imigratórios na atualidade, em especial a partir do ano de 2010. O estudo se caracteriza por ser qualitativo e buscar compreender diretamente com os imigrantes senegaleses, como acontece a dinâmica social que cerca este fenômeno presente no município. A coleta de dados conta com dados secundários e dados primários. Até o presente momento, foram realizadas duas entrevistas com imigrantes. Além disso, revisões de literatura sobre o tema da imigração e cultura, coleta de dados disponíveis em outros trabalhos acadêmicos, contatos com imigrantes nas ruas e observações realizadas no cotidiano do trabalho desses imigrantes.

Entendemos que o processo da pesquisa da maneira que está acontecendo, vem possibilitando uma compreensão mais natural da dinâmica que envolve a imigração, o que faz com que o processo da aproximação com os imigrantes seja conquistado de forma natural e não se torne algo impositivo para os imigrantes, o que consideramos de grande valor para análise da pesquisa. Vale ressaltar sobre as entrevistas que contaram com um roteiro semiestruturado, porém, foi priorizado que os entrevistados falassem o que eles sentissem vontade de falar, ou seja, não ficando preso apenas as perguntas que tínhamos planejados. Outro ponto importante é o pedido de sigilo ${ }^{3}$ por parte dos imigrantes na hora das entrevistas.

Na segunda seção deste trabalho, será apresentado o marco-teórico parcial que a pesquisa vem utilizando. E na terceira parte será apontado os resultados parciais do estudo. Para melhor estruturar o artigo, na primeira parte destes apontamentos serão apresentadas as análises feitas através das observações e depoimentos dos imigrantes, e na segunda parte serão apresentadas as análises realizadas através das entrevistas.

\section{O imigrante e a sociologia das migrações}

Cabe dizer que a sociologia não tem sido a ciência que busca explicar os fenômenos imigratórios. Pode-se dizer também que não existe uma teoria geral das migrações. Atualmente, a geografia é a área do conhecimento que mais se debruça sobre esse problema, principalmente pela sua capacidade interdisciplinar com as questões do espaço, território e sociedade (SAYAD, 1979, p. 56; UEBEL, 2015, p.27). Assim, acredita-se que é necessário aproximarmos a sociologia desse diálogo, buscando a partir de conceitos sociológicos refletir o atual estágio dos movimentos migratórios.

\footnotetext{
3 Afim de manter o sigilo dos entrevistados, eles serão identificados na analise como entrevistado E, e entrevistado $\mathrm{O}$.
} 
Para Abdelmalek Sayad (1979, p.46) o imigrante vive em um estado de contradição e provisoriedade, pois "não se sabe mais se se trata de um estado provisório que se gosta de prolongar indefinidamente ou, ao contrário, se trata de um estado mais duradouro, mas que se gosta de viver com um intenso sentimento de provisoriedade". Podemos explicar isso, com o fato da instabilidade na qual o imigrante está inserido no cotidiano, como por exemplo, a falta de garantias legais da condição de imigrante, ou também o reflexo da conjuntura política de um determinado país e como isso pode afetar os imigrantes que lá estão.

Sayad explica a relação entre a expansão econômica, na qual ele diz ser a grande consumidora da mão de obra de imigrantes, e o sentimento que aqueles interessados tinham em tranquilizar os imigrantes, passando a ideia da necessidade deles, mesmo que "à margem e na parte inferior da hierarquia social" (SAYAD, 1979, p.47). Dessa forma, a mão de obra do imigrante maximiza os custos e gera maiores vantagens para aqueles interessados. Sayad também aponta os motivos que levaram a acontecer na França uma série de garantias legais para os imigrantes da época. Logo, o autor tem uma definição essencial sobre o imigrante: "Um imigrante é essencialmente uma força de trabalho, e uma força de trabalho provisória, temporária, em transito.” (SAYAD, 1979, p.54). Portanto, para Sayad, o imigrante só está na condição de imigrante com a finalidade do trabalho. É possível fazer um paralelo entre os apontamentos e conceitos de Sayad com a teoria marxista e a ideia de um exército de reserva de trabalhadores que é mobilizado quando o sistema demanda.

Segundo Richmond (1988, p.34 citado por SASAKI; ASSIS, 2000, p.5) os trabalhadores nativos não estavam dispostos e preparados para trabalhos duros e com baixa remuneração, assim os empregadores estimulavam a força de trabalho imigrante de países menos desenvolvidos. Por fim, é necessário acrescentar nesse debate sobre imigração, as mudanças nas condições de trabalho e emprego em um mundo globalizado. No atual estágio de desenvolvimento social e econômico, pensar a imigração deve ir além de apenas fugir da pobreza, deve-se levar em consideração a mobilidade geográfica que se tem hoje, os avanços das tecnologias, as flexibilidades nos mercados de trabalho e na forma de consumo das pessoas (SASAKI; ASSIS, 2000, p. 9).

\subsection{Imigração e reconfigurações}

A imigração traz consigo um potencial de transformações. Seja na condição de emigrante ou imigrante os atores desse processo deixam histórias e memórias por onde passam. Com isso, cabe a nós pensarmos no potencial de reconfiguração do social que os processos de migração deixam nas cidades, e o que se pode apontar a partir disso. Dessa 
forma, a partir dos processos de hibridação, é cabível pensarmos essas reconfigurações nas dinâmicas socais. Nestor Canclini (2015, p.19) vai definir o processo de hibridação como "processos socioculturais nos quais estruturas ou práticas discretas, que existiam de forma separada, se combinam para gerar novas estruturas, objetos e práticas”. É possível pensarmos a partir do conceito de Canclini, que os fluxos migratórios podem transformar, criar ou intensificar as mudanças nas estruturas ou práticas de uma sociedade ou de um determinado grupo. Essas reconfigurações podem ser feitas de maneira não planejada, ocorrendo a partir dos fenômenos que passam pela sociedade, sejam eles decorrentes de processos migratórios, turísticos ou comunicacionais (CANCLINI, 2015, p.22). Mas também podemos tratar isso como um grande reflexo da globalização e do atual estágio que se encontra este processo.

\section{A imigração senegalesa em Rio Grande: contexto e trabalho}

O imigrante senegalês ao chegar em outro país, tem contato com o idioma, alimentação e práticas inerentes à cultura dessa região. Segundo os depoimentos de imigrantes e dados de uma pesquisa do IPEA realizada no Rio Grande do Sul (2015, p.113), uma das principais dificuldades dos imigrantes ao chegar no país é o idioma. No centro da cidade de Rio Grande é notável o número de imigrantes senegaleses que trabalham como vendedores ambulantes, carregando em suas maletas (maletas "padronizadas", pois a maioria dos que são vendedores ambulantes possuem), óculos, relógios, bijuterias, meias, luvas e até mesmo algumas tecnologias (variando de acordo com o vendedor).

A imigração senegalesa no município é organizada politicamente. A cidade de Rio Grande conta com uma associação para imigrantes senegaleses, o que demonstra que esses atores estão se organizando politicamente e junto ao cotidiano da cidade. Por essa associação senegalesa que eles podem se manter unidos. Na fala de um dos entrevistados, percebe-se o sentimento de solidariedade que existe entre os imigrantes senegaleses, algo que a associação como organização consegue promover. Outra função da associação senegalesa é a de representação dos imigrantes junto à prefeitura. A associação também se encarrega da organização de eventos religiosos e festas que os senegaleses promovem afim de fortalecer os laços da sua comunidade no município. Podemos considerar a Associação Senegalesa de Rio Grande uma forma de reconfiguração decorrente desse processo imigratório, e que passa a fazer parte do município, assim apresentando traços de uma hibridação das práticas e das estruturas sociais (CANCLINI, 2015, p.19). Outra observação da nossa análise, é a de que esse ator social também passa a ser assimilado no mercado de trabalho local, e como citado nas entrevistas concedidas pelos imigrantes, são poucas as empresas que contratam 
senegaleses. Podemos notar que as vagas para os imigrantes são sempre temporárias, trazendo instabilidade, além de serem vagas de emprego consideradas inferiores as que a população local almeja.

Ao analisarmos as entrevistas neste artigo, a partir de uma categoria central da dinâmica da imigração senegalesa no município que é as relações de trabalho. Esta categoria adotada para a pesquisa possibilita uma articulação entre o problema de pesquisa, a teoria sociológica e as entrevistas realizadas. Assim, como na análise de Sayad acerca da imigração argelina na França, o trabalho é o fator predominante na fala dos dois entrevistados. Se para Sayad (1979, p.56), o imigrante só está na condição de imigrante para trabalhar, e é essencialmente uma força de trabalho, os imigrantes senegaleses entrevistados estão com o objetivo de através da sua força de trabalho no Brasil conquistar uma melhor condição de vida para sua família. Quando perguntado qual era a motivação principal para imigrar para o Brasil/Rio Grande, o primeiro entrevistado, E. responde: "Conseguir dinheiro para ajudar a família, e voltar para o Senegal e investir lá, na agricultura... não fazer com que os meus filhos precisem sair de Senegal para ter uma vida boa. " O segundo entrevistado, O. responde: "Para trabalhar e ajudar minha família... na África não tem emprego, se não for de família com condições não ganhar dinheiro, aqui é melhor." É possível fazermos um paralelo também com o que Sasaki e Assis (2000, p.5) demonstram sobre o olhar que a sociologia econômica dá aos movimentos imigratórios, assim podemos dizer que é preferível (existe um melhor custo) para o imigrante senegalês em arriscar a vida em outro país com o objetivo de ajudar sua família, por mais que existam uma série de dificuldades nesse processo.

Em outra pergunta realizada durante a conversa, as respostas dos imigrantes também foram pela mesma direção. Quando perguntado se existia a intenção de voltar para o Senegal, a resposta do primeiro entrevistado E. foi à seguinte: "A ideia é sempre voltar para o Senegal, eu fico um tempo lá e depois volto, mas quero juntar dinheiro e ir embora para investir em Senegal, não permanecer aqui", a fala do entrevistado vai no sentido da ideia do imigrante com o sentimento de provisoriedade e de uma mão de obra provisória que Sayad (1979, p. 46) apontava. Assim, parece que o imigrante permanece em um estado de não aceitar a condição de ficar como imigrante para sempre. Sayad atrelava essa instabilidade à falta de documentos e ao perigo da deportação que existia em relação aos imigrantes. No caso do nosso estudo, as entrevistas apontaram para certa facilidade em conseguir os documentos provisórios com a Polícia Federal e até a carteira de trabalho, o que seria um fator de estabilidade para a imigração, e talvez ajude a explicar o porquê de o Brasil ser um dos destinos mais visado por esses fluxos imigratórios nos últimos anos. 
A última questão a ser apresentada neste artigo, foi em relação as condições de trabalho que a cidade proporciona ao imigrante senegalês. Quanto a isso a resposta do primeiro entrevistado E. foi: “É difícil, porque empresas não contratam senegaleses, não tem muita oportunidade, ou quando tem, ficar pouco tempo no emprego, é muito difícil trabalhar com carteira assinada aqui." Segundo o mesmo entrevistado, essa é a principal dificuldade, ele completa: “...obter a carteira de trabalho é fácil, é difícil por não ter emprego, e como comerciante é ruim porque acaba trabalhando para sobreviver". O segundo entrevistado também aponta o trabalho como sendo a principal dificuldade para o imigrante senegalês. Em relação ao teor dos depoimentos podemos fazer relação com o que Sayad relatou em sua análise, apontado para a situação do imigrante e posicionando esse grupo como "a margem e na parte inferior da hierarquia social" (SAYAD, 1979, P.47). Relacionado a isso, podemos mencionar crise econômica que existe no país e que reflete na situação dos imigrantes. Sobre a atual condição do país o entrevistado E. diz que: "Foi piorando, em 2013 era bom, 2014 piorou, e 2016 e 2017 está bem ruim, muito complicado para trabalhar". A partir dessa resposta do entrevistado, é interessante pensar no sentido de Sayad (1979, p. 47) que explica que existe o interesse do país em um certo estágio do seu desenvolvimento em ter a mão de obra do imigrante (pois a força de trabalho do imigrante tem a possibilidade de aumentar os lucros, com um baixo custo), e que está de acordo quando pensamos na conjuntura econômica do país no início da década, e também o fator “Brazilian Dream” que era passado para o resto do mundo devido ao bom momento em que o país se encontrava.

Porém, como citado na entrevista, o atual momento é de uma recessão econômica, e o imigrante passa a estar em uma pior condição dentro da estrutura de emprego que poderia a vir a ser ofertada. Porém também podemos entender isso como sendo reflexo da condição do continente africano e do Senegal, e como relatou o entrevistado O: "O trabalho na África é pouco, tem piores condições, aqui no Brasil paga melhor”. Através deste ponto de vista, é possível pensarmos na lógica racional de escolha desse indivíduo na hora de sair de seu país e tentar a vida em outro lugar. Nesse processo, por exemplo, ocorre que essa mão de obra dos imigrantes dinamiza mercados e ao mesmo tempo cria condições de trabalho muitas vezes precárias como, por exemplo, não ter acesso a direitos trabalhistas e sociais de forma plena.

\section{Considerações}

A partir desse trabalho buscou-se refletir sobre o movimento imigratório senegalês em Rio Grande. Retomando a pergunta central do artigo, é possível observar que o imigrante passa a ser um ator relevante para a cidade, e que passa a compor e reconfigurar dinâmicas 
sociais locais e diferentes contextos globais. Nesse processo, por exemplo, ocorre que essa mão de obra dos imigrantes dinamiza mercados e ao mesmo tempo cria condições de trabalho muitas vezes precárias como, por exemplo, não ter acesso a direitos trabalhistas e sociais de forma plena. A Associação de Imigrantes Senegaleses de Rio Grande também auxilia os imigrantes que chegam no município e proporcionam que eles se unam e realizem suas tradições e mantenham sua cultura em outro local. Também não podemos deixar de mencionar as organizações religiosas do município, em especial as irmãs Cáritas de Rio Grande na qual temos conhecimento de projetos sociais que auxiliam os imigrantes na cidade.

Dessa forma, consideramos que a presença de migração massiva para o Brasil é uma das manifestações do atual estágio do capitalismo e permanece como reflexo do crescimento econômico do Brasil na última década. Isso aponta também para a situação de desenvolvimento do continente africano, que foi colonizado e explorado por nações imperialistas, e que nunca permitiu que houvesse uma situação digna de trabalho e emprego paro o seu povo. Portanto, cabe dizer que esse trabalho é início de um estudo que abre grandes possibilidades de investigação sociológica e permite a nós pensarmos uma série de fatores que as imigrações trazem para os contextos locais.

\section{Referências}

CANCLINI, Nestor. Culturas Híbridas: estratégias para entrar e sair da modernidade. $4^{\circ} \mathrm{Ed}$. São Paulo: Edusp, 2015. p. 385.

IPEA. Imigrante, apátridas e refugiados: subsídios para o aperfeiçoamento de acesso a serviços, direitos e políticas públicas no Brasil. Ministério da Justiça. Série pensando o direito, Brasília, n. 57, 2015, p.169.

PEIXOTO, João. As teorias explicativas das migrações: teorias micro e macro-sociológicas. SOCIUS Working Papers, Lisboa, n. 11, 2004, p. 36.

SASAKI, Elisa Massae; ASSIS, Glaucia de Oliveira. Teoria das migrações internacionais. XII ENCONTRO NACIONAL DE ESTUDOS POPULACIONAIS, 7, 2000, Caxambu. Anais... Caxambu, 2000. (Trabalho em anais de congresso)

SAYAD, Abdelmalek. O que é um imigrante? Peuples Méditerranéens, n. 7, abr - jun, 1979, p. 3-23.

UEBEL, Roberto R. G. Analise do perfil socioespacial das migrações internacionais para o Rio Grande do Sul no início do século XXl: Redes, atores e cenários da imigração Haitiana e Senegalesa. Dissertação de Mestrado - UFRGS. 2015, p. 248. 